\title{
LA NEUROFISIOLOGÍA HERMENÉUTICA DEL PODER Y LA IMPARABLE DEMOCRATIZACIÓN DE EUROPA, SEGÚN LA VISIÓN POLÍTICA DE NIETZSCHE
}

\author{
Hermeneutic Neurophysiology of power and the irresistible democratization of \\ Europe, according to Nietzsche's vision of politics \\ Jesús Conill-Sancho \\ Universidad de Valencia
}

RESUMEN: Los principales propósitos de este artículo son los siguientes: en primer lugar, mostrar que la fisiología (incluso la neurofisiología) del poder tiene carácter hermenéutico y relevancia política en el pensamiento de Nietzsche; y, en segundo lugar, tratar del significado de la irresistible democratización de Europa, mediante el análisis de sus consecuencias, en especial, el poder soberano de la voluntad popular y la muerte del Estado. Por último, se introduce el nuevo sentido nietzscheano de la «gran política» como alternativa a la época nihilista de la democracia moderna.

Palabras clave: fisiología - hermenéutica - democracia - política

ABSTRACT: The main purposes of this article are the following: first, to show that physiology (including neurophysiology) of power has hermeneutic character and political relevance in Nietzsche's thought; and, second, to deal with the meaning of the irresistible democratization of Europe, through the analysis of its consequences, especially the sovereign power of popular will and the death of the state. Finally, it is required to introduce Nietzsche's new sense of the "great politics» as an alternative to the nihilist age of modern democracy.

Keywords: Physiology - Hermeneutics - Democracy - Politics

\section{NEUROFISIOLOGÍA HERMENÉUTICA DEL PODER ${ }^{1}$}

La genealogía hermenéutica de Nietzsche convirtió a la fisiología en «señora de todas las otras cuestiones», es decir, el componente fisiológico se convierte en la base decisiva para interpretar los síntomas vitales, incluso el sentido mismo de la política, en especial para comprender el nuevo y peculiar significado que adquirió el término «gran política» en el desarrollo del pensamiento maduro de Nietzsche: «la gran política convierte a la fisiología en señora de todas las otras cuestiones»².

1. Este estudio se inserta en el Proyecto de Investigación Científica y Desarrollo Tecnológico FFI2010-21639-C02-01, financiado por el Ministerio de Ciencia e Innovación (actualmente Ministerio de Economía y Competitividad) y con Fondos FEDER de la Unión Europea, y en las actividades del grupo de investigación de excelencia PROMETEO/2009/085 de la Generalidad Valenciana.

2. KSA XIII 637: 25[1], FP IV 774.

recibido: 13-05-2014 -ESTUDIOS NIETZSCHE I5 (2015), ISSN: 1578-6676, pp. 13-44- aceptado: 06-02-2015 
Por su parte, la fisiología nietzscheana incorpora el componente neurológico, no sólo en lo que se refiere al placer y el dolor ${ }^{3}$, sino también en las valoraciones y en el pensamiento. Las experiencias de placer y dolor son «fenómenos cerebrales $»^{4}$ y las funciones superiores del espíritu están en intrínseca conexión con procesos orgánicos en los que el cerebro ejerce su peculiar función ${ }^{5}$. «No es el cerebro el que piensa $»^{6}$, sino que somos «nosotros los que pensamos» ${ }^{7}$. «Aquí se presupone que el entero organismo piensa, que todas las formaciones orgánicas tienen parte en el pensar, sentir, querer - por consiguiente, que el cerebro es sólo un enorme aparato de centralización» ${ }^{8}$. «El sistema nervioso y el cerebro son un sistema de dirección y un aparato de centralización de innumerables espíritus individuales de distinto rango ${ }^{9}$. Todo nuestro cuerpo piensa y el cerebro centraliza este pensamiento.

Mediante esta perspectiva fisiológica y neurofisiológica se descubre el «inframundo del ideal» y se abre un mundo de «realidades»: «A partir de ese momento no he cultivado de hecho más que fisiología, medicina y ciencias naturales» ${ }^{10}$. Pero el conocimiento que aportan las ciencias naturales - que contribuyen a superar el idealismo- no se entenderá tampoco en sentido positivista sino en un marco hermenéutico, dado que - como veremos a continuación - todos los procesos naturales son considerados como procesos inteligentes de interpretación.

En efecto, Nietzsche entiende todos los procesos biológicos, orgánicos y mentales como procesos inteligentes de interpretación ${ }^{11}$. La interpretación consciente constituye una variedad de la interpretación orgánica del valor biológico ${ }^{12}$. Pues los organismos son organizaciones inteligentes: "Yo presupongo memoria y una especie de espíritu en todo lo orgánico» ${ }^{13}$. "La voluntad de poder interpreta: en la formación de un órgano se trata de una interpretación; la voluntad de poder delimita, determina grados, diferencias de poder. [...] En verdad la interpretación es ella misma un medio para hacerse señor de algo. (El proceso orgánico presupone un permanente INTERPRETAR» ${ }^{14}$; «el interpretar mismo [...] tiene existencia (pero

3. Cf. A. Olivier, «Nietzsche and Neurology»: Nietzsche-Studien 32 (2003), 124-141.

4. KSA IX 559: 11[309], FP II 826.

5. KSA XI 106: 25[356], FP III 515; KSA XI 157: 26[35], FP III 547.

6. KSA VII 598: 27[37], FP I 472.

7. KSA VII 610: 27[77], FP I 480.

8. KSA XI 279-280: 27[19], FP III 622.

9. KSA, XI, 157: 26[36], FP III 547.

10. EH, «Humano, demasiado humano», 3 (Madrid: Alianza, ${ }^{8} 1984$, p. 82).

11. Cf. J. Figl, Interpretation als philosophisches Prinzip, Berlin/New York: de Gruyter, 1982; G. Abel, Nietzsche, Berlin: de Gruyter, 1984; Íd., «Realismus, Pragmatismus, Interpretationismus. Neuere Entwicklungen in der Analytischen Philosophie»: Allgemeine Zeitschrift für Philosophie 13/3 (1988), 51-67; Íd., Zeichen der Wirklichkeit, Frankfurt: Suhrkamp, 2004; Íd., Interpretationswelten, Frankfurt: Suhrkamp, 1993, e Íd., Sprache, Zeichen, Interpretation, Frankfurt: Suhrkamp, 1999; A. Wagner, Kognitive Dimensionen ästhetischer Erfahrung. Eine Untersuchung im Ausgang von Kants Kritik der Urteilskraft, Berlin: Parerga, 2008; J. Simon, Philosophie des Zeichens, Berlin: de Gruyter, 1989 (y la introducción de A. Agud a la edición española, Madrid: Gredos, 1998).

12. Según J.-P. Changeux (Sobre lo verdadero, lo bello y el bien, Buenos Aires: Katz, 2010, p. 49), Nietzsche anticipó la noción de «marcador somático» no consciente del neuropsicólogo Antonio Damasio.

13. KSA XI 117: 25[403], FP III 522.

14. KSA XII 139-140: 2[148], FP IV 122. 
no como un 'ser', sino como un proceso, un devenir) como un afecto» ${ }^{15}$. La interpretación se da como una peculiar forma procesual y afectiva de la voluntad de poder: como «proceso», «devenir» y «afecto»; pero no puede entificarse como un «ser» ${ }^{16}$. Nietzsche acentúa el carácter procesual de toda vida orgánica y del cuerpo humano, al que considera inteligente e interpreta con el modelo de la organización funcional ${ }^{17}$.

A partir de estos textos nietzscheanos Günter Abel entiende la organización como un proceso simplificador y la interpretación en el sentido de una organización ${ }^{18}$. Lo que tienen en común todas las formas de organización es la tendencia a dominar. La interpretación constituye un modo de organización y un medio para hacerse dueño de algo (um Herr über etwas zu werden). La tendencia a dominar es inteligente, pero no tiene un propósito final fijado como si de una «causa» se tratase, sino que consiste en un continuo proceso de organización y reorganización (interpretación y reinterpretación, valoración y transvaloración). En el fondo, de lo que se trata es de un «acontecer»: «el querer-llegar-a-ser-más fuerte por parte de todo centro de fuerza es la única realidad, - no autoconservación, sino apropiación, querer-llegar-a-dominar, querer-llegar-a-ser-más, querer-llegar-a-ser-más-fuerte» ${ }^{19}$.

La interpretación es un proceso de poder que logra organizarse ${ }^{20}$. De ahí que, para Nietzsche, todos los seres sean organizaciones interpretantes, que se rigen por «estimaciones de valor» (en relación con las condiciones de existencia) $\mathrm{y}$ «relaciones de poder ${ }^{21}$. La realidad entera es una multiplicidad de procesos de interpretación, de «interpretaciones empoderadoras», pero cuando todo es considerado en términos de procesos de interpretación, «la distinción entre los procesos físicos [biológicos] y los mentales se disuelve $»^{22}$, porque el cuerpo y la mente se encuentran igualmente penetrados de fuerzas interpretadoras. Hay un «paralelismo» entre «la vida orgánica visible y el obrar y pensar anímico, creativo, invisible», pudiéndose considerar el pensamiento como «síntoma de un acontecer más interno y fundamental $»^{23}$.

Pero para comprender este acontecimiento fundamental de la interpretación no le bastó a Nietzsche la «fisiología del arte», sino que tuvo que llegar más radi-

15. KSA XII 140: 2[151], FP IV 123; KSA XI 560: 36[22], FP III 801.

16. Cf. G. Abel, Nietzsche, cit., pp. 110-129; W. Müller-Lauter, «Der Organismus als innerer Kampf», en Über Werden und Wille zur Macht, Berlin: de Gruyter, 1999, pp. 97-140.

17. Cf. G. Abel, «Interpretatorische Vernunft und menschlicher Leib», en M. Djuric (ed.), Nietzsches Begriff der Philosophie, Würzburg: Königshausen und Neumann, 1990, pp. 10-130; «Interpretationsgedanke und Wiederkunftslehre», en M. Djuric y J. Simon (eds.), Zur Aktualität Nietzsches, vol. II, Würzburg, 1984, pp. 87-104; cf. también W. Müller-Lauter, «Nietzsches Lehre vom Wille zur Macht»: Nietzsche-Studien 3 (1974), 1-60.

18. Cf. G. Abel, «Logik und Ästhetik»: Nietzsche-Studien 16 (1987), 112-148; también A. Olivier, «Nietzsche and Neurology»: Nietzsche-Studien 32 (2003), 124-141.

19. KSA XIII 260-261: 14[81], FP IV 535.

20. Cf. G. Abel, «Nietzsche contra Selbsterhaltung. Steigerung der Macht und ewige Wiederkehr»: Nietzsche-Studien 10/11 (1982), 367-384.

21. KSA XI 503-504: 34[247], FP III 767; cf. A. Olivier, «Nietzsche and Neurology», cit.

22. A. Olivier, «Nietzsche and Neurology», cit., p. 133.

23. KSA XI 157: 26[35], FP III 547; KSA XI 565-566: 36[36], FP III 804-805; KSA XII 139: 2[146], FP IV 122. 
calmente hasta la «fisiología del poder». Y en este nivel se encuentra la base de la peculiar neurofisiología hermenéutica de Nietzsche, quien afirma que es el cuerpo, es decir, el organismo entero, el que piensa: «el entero organismo piensa [...] el cerebro es sólo un enorme aparato de centralización ${ }^{24}$. No en balde Nietzsche defiende que «el cuerpo es una razón» ${ }^{25}$ y considera que «toda vida orgánica [...] está coordinada con un acontecer espiritual ${ }^{26}$. La neurofisiología hermenéutica del poder, tal como la entiende Nietzsche, se sitúa más allá de la división entre fenómenos biológicos y mentales ${ }^{27}$, por cuanto su centro de atención primordial es el universal acontecer interpretativo.

\section{EL HORIZONTE POLÍTICO DE LA GENEALOGÍA HERMENÉUTICA}

La genealogía hermenéutica nietzscheana, como una nueva forma de pensamiento crítico, está ligada a la «fisiología $»^{28}$, a la que recurre Nietzsche para liberarse del idealismo, aunque sin someterse al positivismo cientificista. Pero no se trata sólo de una «fisiología de la estética» o una "fisiología del arte», sino que la hermenéutica nietzscheana se regirá por una «fisiología del poder», con una significativa relevancia política, puesto que tiene como tarea la transformación de las estructuras de poder y las formas de existencia ${ }^{29}$.

Una consecuencia política de su genealogía hermenéutica será la de proponer una sanación de la enfermedad moderna, que hace «vivir de tal modo que ya no tenga sentido vivir» ${ }^{30}$. Precisamente, la "gran política» en el sentido específicamente nietzscheano abrirá un nuevo horizonte político, impulsando un "combate» en favor de hombres que emprendan una nueva «transvaloración». Porque de lo que se trata en último término es de dominar y gobernar el mundo: «Después de que el viejo Dios ha sido eliminado, estoy dispuesto a gobernar el mundo»" ${ }^{31}$. El Anticristo tiene, por tanto, sentido radicalmente político: otra interpretación de la vida, que tiene poder para cambiar los resortes del sentido y del dominio sobre la tierra ${ }^{32}$.

No obstante, debe advertirse que la actitud de Nietzsche ante la política varió a lo largo de su producción ${ }^{33}$. En su primera época destaca la supremacía

24. KSA XI 279-280: 27[19], FP III 622.

25. Za. I, «De los despreciadores del cuerpo» (Madrid: Alianza, ${ }^{12} 1984$, p. 60).

26. KSA XI 157: 26[35], FP III 547; KSA XI 157: 26[36], FP III 547.

27. Cf. G. Abel, «Bewusstsein - Sprache - Natur. Nietzsches Philosophie des Geistes»: Nietzsche-Studien 30 (2001), 1-43; Íd., Zeichen der Wirklichkeit, cit., p. 211.

28. Nietzsche sigue el riguroso enfoque del fisiólogo hasta para comprender la figura de Jesús, interpretando su «habitus fisiológico» como «odio instintivo a la realidad» (AC 29 y 30; Madrid: Alianza, ${ }^{71986, ~ p p . ~ 58-59) . ~ C f . ~ A . ~ U . ~ S o m m e r, ~ F r i e d r i c h ~ N i e t z s c h e s ~ « D e r ~ A n t i c h r i s t » . ~ E i n ~ p h i l o s o p h i s-~}$ cher-historischer Kommentar, Basel: Schwabe, 2000.

29. Cf. T. B. Strong, F. Nietzsche and the Politics of Transfiguration, Berkeley: University of California Press, 1975, p. 187.

30. AC 43 (trad., p. 74).

31. KSA XIII 646: 25[19], FP IV 780; EH, «Por qué soy un destino», 1 (trad., p. 124); también KSA XIII 640: 25[6-1], FP IV 775.

32. Cf. J. Salaquarda, «Der Antichrist»: Nietzsche-Studien 2 (1973), 91-136.

33. Cf. H.-M. Gerlach, «Politik», en H. Ottmann (ed.), Nietzsche-Handbuch, Stuttgart: Metzler, 2000, pp. 499-509. 
concedida a la cultura por encima de la economía y la política. Frente al modelo moderno que se rige por los ideales de la seguridad y el bienestar, Nietzsche siente la «necesidad de vivir libres de política, de lo nacional, de los periódicos, para perfeccionarse» y desea «vivamente la curación de la política» ${ }^{34}$.

Cabría considerar que Nietzsche desarrolla una filosofía supra (o trans)políti$\mathrm{ca}^{35}$, cuando recurre a la cultura «agonal $\aleph^{36}$, aristocrática y heroica, frente a las ideas modernas (aunque hay quienes han querido democratizar el «agonismo» y convertirlo en una clave de la política democrática) ${ }^{37}$. Las ideas que rigen el modo de vida agonística no son la seguridad y el bienestar, sino otro ideal de vida y de humanidad: la del crecimiento, el juego y la divinización o elevación del hombre.

Así, en El nacimiento de la tragedia se presenta una justificación de la existencia y una pretensión de «redención» diferente a la que ofrecen las políticas burguesa y socialista. El punto de referencia nietzscheano se encuentra en la tragedia. Ni el capitalismo ni el socialismo pueden redimir el sufrimiento universal. La justificación de la existencia, la auténtica valoración de la vida se encuentra en la tragedia, que se convierte en una patodicea, porque en la tensión agonal se experimenta la vida y se aboga por ella ${ }^{38}$.

Ahora bien, a mediados de los setenta se produce un cambio significativo. Nietzsche se inclina hacia el modelo del «espíritu libre», hacia una forma peculiar de Ilustración ${ }^{39}$, en la que se valora la autonomía soberana, una cierta forma de emancipación, pero que no hay que confundir con la de la modernidad democrática. Sin embargo, habrá que contar con la permanencia irresistible de la «imparable democratización» y por eso Nietzsche plantea en ocasiones la conveniencia de aprovechar la democracia para superarla. Llama la atención este diagnóstico del proceso democrático, constituyendo uno de los aspectos más innovadores de la peculiar filosofía política de Nietzsche.

\section{LA IMPARABLE DEMOCRATIZACIÓN DE EUROPA}

Es innegable el vigor de la filosofía política de Nietzsche y el sentido vanguardista de la "gran política», así como que sus aportaciones están en estrecha relación con su genealogía hermenéutica y el trasfondo fisiológico que la caracteriza. No se trata, pues, de un panfleto, ni de un mero adorno metafórico ${ }^{40}$, ni tampoco es adecuado despolitizar su pensamiento ${ }^{41}$. Antes bien, la innovadora filosofía

34. KSA VII 776: 32[62] y [63], FP I, 586.

35. Cf. H. Ottmann, Philosophie und Politik bei Nietzsche, Berlin: de Gruyter, ${ }^{2} 1999$, p. 48.

36. Cf. Y. Tuncel, Agon in Nietzsche, Milwaukee, Wisconsin: Marquette UP, 2013.

37. Ibid., cap. 12 (donde se refiere a Chantal Mouffe, Alan Schrift y Lawrence Hatab).

38. Cf. H. Ottmann, Philosophie und Politik bei Nietzsche, Berlin: de Gruyter, ${ }^{2} 1999$, pp. 56-75.

39. H. Ottmann, «Nietzsches Stellung zur antiken und modernen Aufklärung», en J. Simon (ed.), Nietzsche und die philosophische Tradition, vol. 2, Würzburg: Königshausen und Neumann, 1985, pp. 9-33.

40. Cf. M. Warren, Nietzsche and Political Thought, MIT, 1988.

41. Cf. C. Gentili, Nietzsche, Madrid: Biblioteca Nueva, 2004, pp. 410-425; Íd., «¿Nietzsche: ¿político o apolítico?»: Estudios Nietzsche 12 (2012), 105-116. 
política de Nietzsche se centra en las configuraciones del poder y, referida en concreto a la época moderna, en las formas de dominación que caracterizan el imparable proceso democratizador y que siguen expresando la «voluntad de poder».

No obstante, ha sido muy discutida la presunta «filosofía política» de Nietzsche $^{42} \mathrm{y}$, en especial, su posible «teoría de la democracia» ${ }^{43}$. Son conocidas algunas interpretaciones que descalifican la concepción nietzscheana de la política y que destacan su carácter contrario a la democracia moderna ${ }^{44}$. Pero por esa vía se ignora o desvirtúa el núcleo más innovador y original de la filosofía política nietzscheana, al que pertenece no sólo el nuevo sentido que Nietzsche ofrece de la "gran política», sino también muy concretamente su tajante afirmación de que «la democratización de Europa es imparable (unaufhaltsam)»" ¿'Qué significa una semejante afirmación, cuando Nietzsche parece haber defendido una posición contraria a la democracia?

«La democratización de Europa es imparable: quien se le opone emplea, sin embargo para ello precisamente los medios que sólo el pensamiento democrático ha puesto al alcance de todos, y hace estos medios más manejables y eficaces; y los por principio opuestos a la democracia (me refiero a los revolucionarios) no parecen existir más que para, por el temor que infunden, empujar a los distintos partidos cada vez más velozmente por la vía democrática».

Ahora bien, que la democratización sea «imparable» no quiere decir que sea del todo deseable, porque, según Nietzsche, a la vista de los que ahora trabajan por ese futuro democrático, tal proceso puede dar miedo: «Hay algo de desolado y uniforme en sus rostros, y el polvo gris parece haber penetrado hasta en su cerebro».

Ahora bien, «es posible que algún día la posteridad se ría de estos nuestros miedos y acaso piense del trabajo democrático de una serie de generaciones lo mismo que nosotros de la construcción de diques y murallas»: que se trata de una actividad que «llena de polvo» y hace «un poco imbéciles»; sin embargo, a continuación, Nietzsche se pregunta: «Pero équién desearía por ello que no se hubiese hecho todo esto?».

La respuesta a esta última pregunta de Nietzsche se encuentra a renglón seguido: «Parece que la democratización de Europa es un eslabón en la cadena de

42. Cf., por ejemplo, M. Warren, Nietzsche and Political Thought, cit.; K. Ansell-Pearson, An Introduction to Nietzsche as political thinker. The perfect nibilist, Cambridge: Cambridge UP, 1994.

43. Cf., por ejemplo, A. D. Schrift, «Nietzsche for Democracy?»: Nietzsche-Studien 29 (2000), 220-233; D. Dombowsky, «A Response to Alan D. Schrift's 'Nietzsche for Democracy?'»: Nietzsche-Studien 29 (2000), 220-233 y 31 (2002), 278-297; Th. H. Brobjer, «The Absence of Political Ideals in Nietzsche's Writings»: Nietzsche-Studien 27 (1998), 300-318; L. J. Hatab, A Nietzschean Defense of Democracy, Chicago: Open Court, 1995; E. Kiss, «Friedrich Nietzsche - A Theoretician of Modern Democracy»: Revista Portuguesa de Filosofía 57 (2001), 269-284; N. González Varela, Nietzsche contra la democracia, Barcelona: Montesinos, 2010; Y. Tuncel, Agon in Nietzsche, cit., cap. 12.

44. A. Baeumler, Nietzsche, der Philosoph und Politiker, Leipzig: Reclam, 1931; G. Lukács, El asalto a la razón, Barcelona: Grijalbo, 1968; F. Appel, Nietzsche contra Democracy, Ithaca: Cornell University, 1999.

45. MA II, WS $\$ 275$ (Madrid: Akal, 1996, p. 200). 
esas tremendas medidas profilácticas que son el pensamiento de la nueva época y que nos separan de la Edad Media».

Según Nietzsche, el proceso democratizador acontece en una época en la que se está preparando el «futuro» de los «fértiles campos de la cultura», en contra del «esclavizamiento corporal y espiritual». Es «la época de las construcciones ciclópeas», de tal manera que las medidas profilácticas preparen bien (integralmente) el espíritu del «artista supremo de la jardinería, que sólo podrá dedicarse a su tarea propiamente dicha cuando aquélla esté perfectamente consumada». Pero, por el momento, debido al tiempo y esfuerzo que se requieren para los cambios históricos profundos, es decir, entre los medios y el fin que se persigue, Nietzsche considera que «no cabe reprochar con demasiada dureza» a los que trabajan por la democracia en su época que consideren como «fin y última meta» lo que no son más que «medidas profilácticas».

A diferencia de otras filosofías políticas, la de Nietzsche no otorga ningún valor último a ningún sistema político, tampoco a la democracia, sino que incluso ésta es una posible ocasión para llevar a cabo las supremas aspiraciones humanas. Nietzsche evalúa los sistemas políticos desde la perspectiva de lo que pueden aportar a la radical emancipación, de ahí que los considere y distinga según su «potencial profiláctico» ${ }^{46}$, es decir, según su capacidad para preservar de la enfermedad moderna y conservar la buena salud.

De hecho, Nietzsche no optó por ninguno de los diversos movimientos políticos de su tiempo: «No somos en absoluto 'liberales', ni trabajamos por el 'progreso'; no necesitamos en primer lugar tapar nuestros oídos para precavernos de las sirenas futuras del mercado; lo que ellas cantan, 'derechos iguales', 'sociedad libre', 'que no haya ni señores ni siervos', ieso no nos seduce! No sostenemos sin más ni más como deseable que se establezca el imperio de la justicia y de la buena inteligencia sobre la tierra». No se siente a gusto en una época que se tiene por «más humana» («la más humana»), pero que Nietzsche considera «expresión» («mascarada») de un profundo debilitamiento, de una enfermedad que se adorna con la «religión de la compasión». Por eso, afirma: «No somos humanitarios, no nos atreveríamos nunca a permitirnos hablar de nuestro 'amor a la humanidad' [...] No, no amamos a la humanidad $»^{47}$.

Lo que se considera Nietzsche es un apátrida, de raza y procedencia diversa, deseoso de «nuevos órdenes» a partir de Europa: «En una palabra [...], somos buenos europeos, los herederos de Europa [...]; en cuanto tales procedemos del cristianismo y estamos en contra del mismo, precisamente porque procedemos de él, porque nuestros antepasados cristianos eran de una honradez del cristianismo sin miramientos, que ha sacrificado voluntariamente sus bienes, su sangre, su situación y su patria a su fe. Nosotros...hacemos lo mismo. ¿En favor de qué? ¿En favor de nuestra incredulidad? [...] No [...]. El sí oculto en vosotros es más fuerte que todos los no o acasos de que padecéis con vuestro tiempo; y si tuvieseis que estar en la mar, como emigrantes, a vosotros también os fuerza a ello... una $f e . . . »^{48}$. Nietzsche defiende la unidad de Europa con los «buenos europeos» y la apertura hacia un nuevo tipo de «hombre superior», frente a la «insania» de los

46. Cf. E. Kiss, «Friedrich Nietzsche - A Theoretician of Modern Democracy», cit.

47. FW $\$ 377$ (Madrid: Espasa-Calpe, 1986, pp. 280-281).

48. FW $\$ 377$ (trad., pp. 281-282). 
nacionalismos, los «políticos de mirada corta» y la «política disgregacionista» ${ }^{49}$, entendiendo por «Europa» no un mero sentido geográfico, sino un horizonte cultural que incluye a América, por tener un «pasado común en Grecia, Roma, el judaísmo y el cristianismo $»^{50}$.

\section{LA MUERTE DEL ESTADO}

Además de la crítica a las diversas tendencias políticas existentes en su época, cabría destacar algunas peculiaridades de la filosofía política de Nietzsche que lo sitúan a la vanguardia de su tiempo, entre las que destaca su previsión de la muerte del Estado.

En primer lugar, el tratamiento nietzscheano de la imparable democratización de Europa tiene más valor del que parece a primera vista, dado que la época de Nietzsche no se caracteriza por el éxito de la democracia política, sino por las dificultades de instaurarla, debido a que las tendencias dominantes no eran tan democratizadoras como podría suponerse (bonapartismo en Francia, Bismarck en Alemania, creciente difusión de doctrinas revolucionarias y subversivas). Es destacable, pues, la capacidad de Nietzsche para comprender las tendencias operantes en el trasfondo de los procesos efectivos en la realidad política y social de su tiempo.

En segundo lugar, una peculiar originalidad del enfoque nietzscheano se encuentra en la atención que presta al factor del poder como tal en el proceso de la democratización moderna de Europa (comprendiéndolo en un sentido diferente al del paradigma marxista, que ha sido dominante durante mucho tiempo $)^{51}$. Por ejemplo, en alguna ocasión insiste en que «no hay en el socialismo, en el caso de que éste sea efectivamente el levantamiento de los secularmente oprimidos, sojuzgados, contra sus opresores, un problema de derecho [...] sino sólo un problema de poder (Macht)", no una cuestión de deber (sollen), sino de poder (können $)^{52}$.

Nietzsche considera que la democracia constituye un concepto nuevo de gobierno, pero en la que se sigue distinguiendo entre «esferas de poder» separadas, una más fuerte, superior, y otra más débil, inferior, que negociarían y se pondrían de acuerdo, una vez establecidas las «relaciones de poder». Lo que ocurre es que ahora se propone «la forma constitucional como un compromiso entre gobierno y pueblo», con lo cual se está hablando "conforme a un principio que tiene su razón en la historia» (de ahí el componente de «sinrazón» que conlleva, «sin el que nada humano puede existir»), pero debe aprenderse («conforme a un principio que ha surgido puramente de la cabeza y que aún tiene que hacer historia») «que el gobierno no es nada más que un órgano del pueblo».

Ahora bien, Nietzsche advierte de que «antes de aceptar esta formulación, hasta aquí antihistórica y arbitraria, aunque más lógica, del concepto de gobierno», han de sopesarse «las consecuencias», porque «la relación entre pueblo y gobierno es la relación ejemplar», que sirve de modelo a todas las otras rela-

49. JGB $\$ 256$ (Madrid: Alianza, ${ }^{4} 1978$, p. 214).

50. MA II, WS $\$ 215$ (trad., p. 186).

51. Cf. E. Kiss, «Friedrich Nietzsche - A Theoretician of Modern Democracy», cit.

52. MA $\$ 446$ (trad., p. 218). 
ciones y formas de trato (profesor/alumno, señor/servidumbre, padre/familia, general/soldado, patrón/aprendiz, etc.). «Todas estas relaciones se están modificando algo hoy en día bajo el influjo de la dominante forma constitucional de gobierno: se están convirtiendo en compromisos ${ }^{53}$. Es decir, bajo el influjo ejemplar de la forma constitucional de gobierno se están democratizando todas las relaciones sociales y hasta personales en las que se ejerce el poder, a través de una peculiar relación de compromiso, de arreglos y acuerdos, en los que hay que tener disposición a transigir para lograr una solución de compromiso, llegando a algún pacto, en forma de componenda, convenio y/o contrato.

Nietzsche está vislumbrando un proceso de transformación democratizadora (por la vía de las relaciones y soluciones de compromiso) que va más allá de lo estrictamente político y que afecta a la mentalidad de una época, en la que se insertan las nuevas relaciones políticas y formas de gobierno. Ese es el sentido del final del parágrafo 450 de Humano, demasiado humano: «iCómo se invertirán y desplazarán, cambiarán de nombre y de ser [las relaciones] cuando ese concepto [de gobierno] completamente nuevo se haya adueñado por doquier de las mentes!». Y ante la perspectiva de este proceso y sus previsibles consecuencias, que bien puede durar «un siglo», Nietzsche dice desear - y creo que recomienda- «precaución»y «evolución lenta». Pues, igual que ha perdurado «la vieja mentalidad del esclavo en relación con el amo», configurando «una relación ejemplar arbitrariamente traspuesta al matrimonio, a la actitud hacia los criados, los obreros, los camaradas de partido, los alumnos de un maestro", así en los nuevos tiempos modernos la relación ejemplar que servirá de modelo para todas las relaciones será la forma constitucional de gobierno que convertirá (también de modo arbitrario) todas las relaciones en «compromisos». Nietzsche sospecha que se conformará así la nueva mentalidad que sustenta y acompaña el proceso de democratización moderna.

En tercer lugar, Nietzsche expone algunas de las consecuencias que cabe esperar de este proceso democratizador, respondiendo a su propia pregunta: «iY si empieza a calar esa versión del concepto de gobierno enteramente distinta que se enseña en Estados democráticos?» ${ }^{54}$. La primera consecuencia será la de ver al Estado «nada más que como el instrumento de la voluntad popular», «exclusivamente una función del único soberano, del pueblo» ${ }^{55}$. Para comprender la nueva situación, la conversión del Estado en instrumento de la voluntad popular como consecuencia del proceso democratizador, Nietzsche recurre en este contexto a una comparación con la religión: «Cuando el Estado ya no pueda extraer ningún provecho de la religión [...] se hará necesario el recurso de tratar la religión como asunto privado y remitirla a la conciencia y al hábito de cada individuo». Algo parecido ocurrirá con el Estado. Tras la etapa ardorosa de un «entusiasmo casi fanático por el Estado» y las consiguientes «luchas de transición, acaso de larga duración», remitirá el entusiasmo por el Estado y se quebrará «la relación respetuosa y piadosa» con el Estado: «Los individuos sólo ven en él el aspecto en que puede serles útil o perjudicial, y tratan por todos los medios de lograr

53. MA $\$ 450$ (trad., p. 219).

54. MA $\$ 472$ (trad., p. 226).

55. MA $\$ 472$ (trad., pp. 226-227). 
influencia sobre él $\aleph^{56}$. Al haber perdido el Estado la irradiación pseudorreligiosa de una «institución supramundana», «nadie siente ya ante una ley otra obligación que la de inclinarse momentáneamente ante el poder (Gewalt) que promulgó una ley; pero en seguida se procede a minarla mediante un nuevo poder $(G e-$ walt), una nueva mayoría por constituir».

Como consecuencia de estos cambios históricos surge, según Nietzsche, una creciente «desconfianza hacia todo lo que gobierna», lo cual impele a la gente hacia una nueva resolución: derogar el concepto de Estado y superar la oposición entre "privado y público». En relación con este último aspecto anticipa Nietzsche lo siguiente: «Las sociedades privadas absorben paso a paso los asuntos de Estado: incluso el más pertinaz resto que queda del antiguo trabajo del gobierno [...] acaba un día por ser encargado a los empresarios privados». El resultado final, según Nietzsche, es el siguiente: «El menosprecio, la decadencia y la muerte del Estado, la emancipación de la persona privada (me guardo de decir: del individuo) son la consecuencia del concepto democrático del Estado; en esto consiste su misión $»^{57}$.

Por consiguiente, en la perspectiva nietzscheana, «la soberanía del pueblo [...] sirve para ahuyentar hasta el último hechizo y superstición» en el ámbito de los sentimientos religiosos que se esconden en el fondo del respeto (en forma de veneración, adoración, entusiasmo y fanatismo) por el Estado. Pero «si la religión desaparece, el Estado perderá irremisiblemente su antiguo velo de Isis y ya no infundirá respeto». En consecuencia, «la democracia moderna es la forma histórica de la decadencia del Estado» ${ }^{58}$.

Ante el proceso democratizador que lleva a la decadencia y muerte del Estado, Nietzsche reflexiona sobre la experiencia histórica y confía en que la sagacidad y el interés de la gente sepa inventar una nueva solución en cada momento. Porque así ha ocurrido a lo largo de la historia: «Cuántos poderes organizadores (organisirende Gewalt) ha visto ya la humanidad extinguirse»: por ejemplo, el poder (Gewalt) de la raza y el de la familia. Pues, igual que estos poderes han perdido el dominio y se ha debilitado su importancia, algo así sucederá con el Estado, muy a pesar del temor y la aversión que esta idea suscita en algunos.

De ahí que «la perspectiva que resulta de esta segura decadencia [del Estado] no es en todos los respectos pesimista: la sagacidad (Klugheit) y el egoísmo (Eigennutz) de los hombres son las más desarrolladas de sus cualidades; cuando el Estado deje de corresponder a las exigencias de estas fuerzas, no aparecerá el caos ni mucho menos, sino que una nueva invención más adecuada aún que el Estado triunfará sobre el Estado».

Pero una condición básica para que la política se transforme en sentido emancipador es que las opciones estén orientadas por el largo plazo y no por el corto, como ocurre en la democracia: «A todas las medidas que pueda imponer un gobierno les falta la garantía de su duración; se retrocede ante empresas que deberían tener un crecimiento tranquilo durante décadas, siglos, para rendir frutos maduros ${ }^{59}$. La tendencia dominante en la democracia moderna es la de

59. MA $\$ 472$ (trad., p. 227). 
relegar los proyectos a largo plazo y lo que impera en todos los órdenes es el corto plazo $^{60}$. Y, además, como cada cual busca lo que pueda serle beneficioso y cada vez más influencia para lograr sus propósitos, se acrecienta enormemente la competencia y los cambios se producen «demasiado rápidamente»: «demasiado ferozmente se despeñan montaña abajo unos a otros apenas han alcanzado la cima» ${ }^{61}$.

Lo que hace falta a la vista de las «ideas modernas» es ampliar la «responsabilidad», para lo que se requiere «fortaleza de la voluntad», «dureza y capacidad para adoptar resoluciones largas», ser capaz de estar «en contradicción» con el ideal de hoy, ser «inactual» frente a las ideas modernas y los «ídolos del día»; sólo así es posible hoy tener "grandeza» y ser «aristócrata», "cuando en Europa es el animal de rebaño el único que recibe y que reparte honores» ${ }^{62}$.

\section{DEMOCRATIZACIÓN, «MUERTE DE DIOS» Y NIHILISMO}

Existe una vinculación entre la imparable democratización de Europa y la proclamación de la «muerte de Dios» ${ }^{63}$, que es imposible desarrollar aquí, porque abre un campo más amplio que el de la estricta filosofía política, como es el de la filosofía de la historia, la cultura y la religión. No obstante, es ineludible señalar su estrecha vinculación.

La muerte del Estado es la consecuencia del concepto democrático del Estado. Pues la soberanía del pueblo sirve para ahuyentar la superstición en el orden de los sentimientos religiosos que sostienen la política. La creencia en un orden divino de las cosas políticas y en el misterio del Estado es de origen religioso, por consiguiente cuando la religión empieza a morir (extinguirse), se resquebrajan los «cimientos» del Estado, y «si la religión desaparece, el Estado perderá irremisiblemente su antiguo velo de Isis y ya no infundirá respeto» ${ }^{64}$ [repetido, véase más arriba].

Se plantea en este contexto uno de los asuntos más importantes en el proceso democratizador moderno (sobre todo, en Europa) y todavía candente: la relación entre democracia y religión en el peculiar horizonte de la anunciada por Nietzsche «muerte de Dios». En primer lugar, al convertirse en un asunto privado, la religión se refuerza por otras vías: «el sentimiento religioso aparece fortificado, en la medida en que ahora irrumpen y se desenfrenan hasta el extremo arrebatos del mismo recónditos y reprimidos, a los que el Estado, involuntaria o intencionadamente, no suministraba aire vital». Y, por otra parte, al hacerse cuestión privada, surge una gran cantidad de «sectas» y, conforme a la expresión de Nietzsche, «se sembró una multitud de dientes de dragón» ${ }^{65}$.

Otra importante cuestión que se plantea es la relación entre poder y derecho, en el horizonte de la «muerte de Dios». Nietzsche se sitúa prioritariamente en el

60. Cf. E. Kiss, «Friedrich Nietzsche - A Theoretician of Modern Democracy», cit., p. 280.

61. MA $\$ 472$ (trad., p. 227).

62. JGB $\mathbb{2} 212$ (Madrid: Alianza, ${ }^{4} 1978$, p. 157).

63. Cf. E. Kiss, «Friedrich Nietzsche - A Theoretician of Modern Democracy», cit., p. 274; V. Soromenho-Marques, «Nietzsche como pensador da política»: Revista Portuguesa de Filosofía 57 (2001), 247-267.

64. MA $\$ 472$ (trad., p. 228).

65. MA $\$ 472$ (trad., p. 227). 
orden del poder (Macht), también en relación con el proceso democratizador. Y para resolver las cuestiones de poder Nietzsche recomienda saber con qué «fuerza» se cuenta y «ante cualquier fuerza — aun la más peligrosa-, la humanidad debe pensar en hacer de ella un instrumento de sus propósitos» ${ }^{66}$. Si aplicamos la perspectiva nietzscheana habría que decir que el derecho se adquiere cuando, tras estallar la guerra entre los poderes imperantes, «el cálculo prudente de la mayor conservación y conveniencia posible hace nacer [...] el deseo de un acuerdo». Pues, según Nietzsche, «sin acuerdo, no hay derecho». Mientras no haya acuerdo, tampoco habrá derechos, ni ningún «deber», sino poder.

Igual que el derecho depende del poder, asimismo la política: son sólo medios pasajeros, no son fines; ejercen una función, son instrumentos en la lucha por el poder. Pues «no hay nada en la vida que tenga valor fuera del grado de poder ${ }^{67}$. Cuando sucumbe la creencia en Dios y en la moral cristiana (que protegían del nihilismo), sólo queda el dinamismo del poder, sus oscilaciones, tensiones y equilibrios.

El nihilismo constituye otro elemento clave en la concepción nietzscheana de la política moderna, debido a que expresa el modo de sentir y vivir en el horizonte moderno de la «muerte de Dios» ${ }^{68}$. Pues la crisis de valores producida por su prolongado proceso conduce a la humanidad, en especial a Europa, a una búsqueda trágica de valores e ídolos alternativos. Nietzsche interpreta el creciente fervor ideológico-político moderno como un sustitutivo del Dios cristiano, cuya ausencia produce un enorme vacío vital, que se intenta llenar con la mascarada nihilista de las ideas modernas. Es así como la política se convierte en un terreno abonado para que surjan los nuevos ídolos; es lo que ha ocurrido, por ejemplo, con el Estado y el nacionalismo ${ }^{69}$. O bien asimismo con la ciencia moderna: «Ironía ante los que creen al cristianismo superado por las modernas ciencias naturales. Los juicios de valor cristianos no están en absoluto superados por ellas. 'Cristo en la cruz' es el símbolo más sublime - aún hoy— ’0 $^{70}$ Pero entonces, ¿cómo vivir en un mundo orientado por la «muerte de Dios»? He aquí un problema individual, cultural y político, al que Nietzsche denomina con el término «nihilismo», un desafío trágico que Europa tendrá que afrontar para replantearse sus objetivos decisivos, que tienen carácter ecuménico y cosmopolita ${ }^{71}$ : «la época trágica para Europa: condicionada por la lucha contra el nihilismo» ${ }^{72}$.

A pesar de todas las críticas al proceso democratizador, algunos estudiosos de la dimensión política de la obra nietzscheana consideran que tanto la

66. MA $\$ 446$ (trad., p. 218)

67. KSA XII, 215: 5[71-10], FP IV166.

68. V. Soromenho-Marques, «Nietzsche como pensador da política», cit.

69. JGB $\$ 241,242,251$ y 256 . Ante el problema del nacionalismo y de Europa, que entiende por «nación» «los hombres que hablan una misma lengua y leen los mismos periódicos [...] y también les gustaría muchísimo tener un origen e historia común; lo cual, sin embargo, no ha tenido éxito ni con la peor falsificación del pasado» (KSA XI 489: 34[203], FP III 758), Nietzsche propone superar el «sentimiento nacional», la «patriotería», sus «atávicos accesos» y «retornar a la razón», al «buen europeísmo» (JGB $\$ 241$, trad., pp. 192-193).

70. KSA XII 108: 2[96], FP IV 104.

71. Cf. K. Ulmer, «Nietzsches Philosophie in ihrer Bedeutung für die Gestaltung der Weltgesellschaft» (ed. W. Stegmaier): Nietzsche-Studien 12 (1983), 51-79.

72. KSA XII 202: 5[50], FP IV 159. 
«imparable democratización» como la «muerte de Dios» son «oportunidades históricas» para la emancipación ${ }^{73}$, que pueden tener un «impacto traumático», pero también albergar «grandes promesas» ${ }^{74}$, empezando por la emergencia del «pensamiento de un progreso de todos los progresos»: «iA los hombres les está todavía reservada mucha alegría de la que a los actuales no les ha llegado todavía el aroma! iY podemos ciertamente prometernos esta alegría, más aún, augurarla y conjurarla como algo necesario, siempre que el desarrollo de la razón humana no se detenga!»75. De manera que, aunque en principio resulte extraño para la concepción nietzscheana estándar, la democracia moderna constituye una oportunidad histórica que podría aprovecharse inteligentemente (sagazmente) para la emancipación. Las fuerzas democráticas podrían convertirse en un instrumento para su propia autosuperación y, por tanto, la imparable democratización puede ponerse al servicio de más altas - y radicales- metas emancipadoras o liberadoras.

No obstante, la respuesta política a la época nihilista se encuentra en la «gran política», en el sentido nietzscheano. Nietzsche se encontró con este término, que usó primero con sentido irónico asociándolo a la política de Bismarck $^{76}$, pero al que acabó dándole un nuevo significado ${ }^{77}$, renovador (incluso agitador) y anticipador de un futuro, por el que todavía cabe alguna esperanza y que constituye un capítulo sumamente característico de la filosofía política nietzscheana ${ }^{78}$.

\section{DEL DEMOCRATISMO MODERNO A LA «GRAN POLÍTICA»}

Como hemos visto, según Nietzsche, uno de los componentes de la modernidad es el democratismo, que constituye una forma decadente de organización social, que la lógica de la modernidad ha ido imponiendo de un modo «imparable». Pero, también según Nietzsche, no basta la democracia para llegar a ser libre, ni puede servir de horizonte utópico ni de canon crítico para orientar la vida política; más bien, produce náuseas a cierta sensibilidad, porque ha degenerado los instintos y las instituciones, ha obturado el futuro de la humanidad. De manera que, para abrirse a una nueva aurora, habría que ir «más allá de la democracia».

Nietzsche quiere rescatar el sentido vital del «ensayo», del experimento y la tentación, propio del «espíritu libre», porque al margen del capitalismo y el

73. Cf. E. Kiss, «Friedrich Nietzsche - A Theoretician of Modern Democracy», cit., pp. 269-284; V. Soromenho-Marques, «Nietzsche como pensador da política», cit.

74. Cf. E. Kiss, «Friedrich Nietzsche - A Theoretician of Modern Democracy», cit., p. 279.

75. MA II WS $₫ 183$ (trad., p. 174).

76. MA I 481 («La gran política y sus costes»); M 189 («La política grande»); JGB 241 y 254; GD, «Lo que los alemanes están perdiendo», 4 (Madrid: Alianza, 1984, p. 80); KSA XIII, 540: 19[1-3]. Cf. V. Soromenho-Marques, «Nietzsche como pensador da política», cit., pp. 266-267.

77. KSA XIII 637-638 y 640: 25[1] y [6-1], FP IV, 773-774 y 775.

78. Cf. U. Marti, «Grosse Politik», en H. Ottmann (ed.), Nietzsche Handbuch. Leben-WerkWirkung, Stuttgart: Metzler, 2000, pp. 248-250; H. Ottmann, Philosophie und Politik bei Nietzsche, cit., parte III; J. Conill, El poder de la mentira. Nietzsche y la politica de la transvaloración, Madrid: Tecnos, 1997, parte III; L. Sagols, «La gran política y el don de la humanidad»: Estudios Nietzsche 1 (2001), 103-118. 
socialismo, a los que considera hermanos, lo que hace realmente falta es una transformación del «sentido», más allá de las organizaciones políticas típicamente modernas. La tarea del «espíritu libre» es la transformación del sentido vital, rescatando la raíz de las formas de vida, que las instituciones modernas amenazan erradicar en nombre de la libertad y de la justicia igualitaria, pero en realidad están regidas por la seguridad y el bienestar de una cierta mayoría. Se trata de las ideologías del «rebaño autónomo» ${ }^{79}$, que el «espíritu libre» rebasará por su afán de radicalizar la autonomía individual. Desde esta nueva perspectiva nietzscheana surge una peculiar Ilustración ${ }^{80}$, que plantea de nuevo «el problema de la civilización» y el «regreso a la naturaleza», cuyo sentido nietzscheano no significa un «regreso", sino una «elevación».

La filosofía política que Nietzsche despliega en su última época se opone a la institucionalización política y jurídica del igualitarismo moderno a través del proceso democratizador, puesto que éste disuelve la autoridad natural. El propósito de la «gran política» lo constituirá el cuidado por el futuro y la elevación del hombre, a fin de que éste pueda alcanzar sus posibilidades supremas y llegue verdaderamente a ser libre.

La tarea de la "gran política» consiste en determinar el hacia dónde y el para qué. Sus supuestos son la transvaloración de los valores y la nueva legislación de los nuevos filósofos (creadores). Y todo ello va dirigido a la cría (Züchtung) de hombres de calidad superior, al establecimiento de la jerarquía natural como condición de crecimiento en una sociedad aristocrática, donde se potencia el sí-mismo, porque sólo cada cual se pertenece a sí mismo. De este modo se plasma la voluntad de actuar a favor del «superhombre», es decir, la superación del nihilismo. «El tiempo de la política pequeña ha pasado: ya el próximo siglo trae consigo la lucha por el dominio de la tierra, la coacción a hacer una política grande» ${ }^{81}$. Estas alusiones a la gran política se recogen en Ecce homo: «El concepto de política queda entonces totalmente absorbido en una guerra de los espíritus, todas las formaciones de poder de la vieja sociedad saltan por el aire; todas ellas se basan en la mentira: habrá guerras como jamás las ha habido en la tierra. Sólo a partir de mí existe en la tierra la gran política» ${ }^{82}$.

La nueva forma nietzscheana de entender la "gran política» se opone a la democratización moderna de Europa, porque ésta disuelve la jerarquía natural en favor del igualitarismo, desenmascara la ficticia libertad democrática que desemboca en el nihilismo. Por eso, otorgar a la existencia un nuevo sentido y que dominen aquellos que puedan dar sentido a la existencia son movimientos propios del significado de la peculiar filosofía política de Nietzsche, expresada en la «gran política» y cuyos ingredientes son el orden del «sentido» y del «dominio» de la tierra.

79. JGB $\$ 202$ (trad., p. 134).

80. KSA XII 402-403 y 449: 9[116] y 9[185], FP IV 271 y 295; H. Ottmann, Philosophie und Politik bei Nietzsche, cit., p. 162; Íd., «Nietzsches Stellung zur antiken und modernen Aufklärung», en J. Simon (ed.), Nietzsche und die philosophische Tradition, vol. 2, Würzburg: Königshausen und Neumann, 1985, pp. 9-33; J. Conill, El poder de la mentira, cit., pp. 174 ss.

81. JGB $\$ 208$ (trad. p. 150).

82. EH, «Por qué soy un destino», 1 (trad., p. 124); cf. C. L. Roser, «La gran política y la superación del nihilismo en F. Nietzsche»: Quaderns de filosofía i ciencia 13/14 (1988), 41-52. 
En la gran política se recupera la figura de la lucha agonal ${ }^{83}$, que tiene como centro el tipo de hombre y cuya tarea consiste en la formación del hombre para su grandeza y dominio sobre la tierra. Una nueva paideia posmoderna de los futuros «señores de la tierra $»^{84}$. La gran política nos abre la posibilidad de transfigurar la existencia sobre la tierra, y la metáfora del «superhombre» nos indica que el futuro está abierto para el «gran» individuo. «El hombre es una cuerda tendida entre el animal y el superhombre», su grandeza «está en ser un puente y no una meta», «el hombre es algo que debe ser superado». "Yo quiero enseñar a los hombres el sentido de su ser: ese sentido es el superhombre» ${ }^{85}$.

En la formación de las individualidades selectas, expresadas mediante la metáfora del superhombre, opera una «selección» no darwiniana ${ }^{86}$, ya que ésta todavía cree en el progresismo evolucionista. Ciertamente, para desarrollar una «superhumanización» que no vaya contra la naturaleza, es ineludible un componente biológico, que forma parte de la noción de «cría» (Züchtung), pero cuyo sentido integral incorpora también la dimensión educativa para la afirmación de la vida ${ }^{87}$, tal como viene determinada por la doctrina del Eterno Retorno ${ }^{88}$. El aspecto biológico ${ }^{89}$, con especial énfasis en la fisiología —y que aquí hemos ampliado al nivel neurofisiológico-, está abundantemente atestiguado no sólo en las obras publicadas, sino en fragmentos como el citado desde un comienzo: «la gran política convierte a la fisiología en señora sobre todas las otras cuestiones» ${ }^{90}$.

$\mathrm{La}$ «gran política» trae consigo una nueva "guerra de los espíritus» (Geisterkrieg), en la que se expresa la voluntad de poder y sus exigencias de jerarquía y aristocracia ${ }^{91}$. El recurso a la fisiología de la vida equivale a una «fisiología del poder», de tal manera que la gran política consiste en una fisiología hermenéutica del poder. La nueva filosofía política nietzscheana cuenta con una especie de fisiología política para la tarea de criar (formar) al hombre como dueño soberano de la tierra, que hasta podría servirse de la Europa democrática para disponer de su destino ${ }^{92}$. Esta nueva paideia ligada a la fisiología educará para la afirmación de la vida y llenará el vacío provocado por la «muerte de Dios» y el consiguiente nihilismo (pasivo o reactivo). Para comprender esta nueva orientación vital hacia los «señores de la tierra», Nietzsche nos recuerda: "Cada uno de nosotros desea ser señor en lo posible de todos los hombres, preferiblemente Dios'. Esta actitud tiene que seguir existiendo» ${ }^{93}$.

83. Cf. Y. Tuncel, Agon in Nietzsche, cit.

84. Cf. H. Ottmann, Philosophie und Politik bei Nietzsche, Berlin: de Gruyter, ${ }^{2} 1999$.

85. Za, Prólogo 3, 4 y 7 (trad., pp. 34, 36 y 42).

86. J. Gayon, «Nietzsche and Darwin», en J. Maienschein y M. Ruse (eds.), Biology and the Foundations of Ethics, Cambridge: Cambridge UP, pp. 154-197.

87. KSA XI 580-583: 37[8], FP III 814-815.

88. Cf. H. Ottmann, Philosophie und Politik bei Nietzsche, cit., p. 263; P. D’Iorio, La Linea e il Circolo. Cosmologia e filosofia dell' eterno ritorno in Nietzsche, Genova: Pantograf, 1995.

89. Cf. M. Stingelin, «Nietzsche und die Biologie»: Nietzsche-Studien 32 (2003), 503-513.

90. KSA XIII 638: 25[1], FP IV 774.

91. KSA XII 96-97: 2[76], FP IV 97-98; KSA XIII 612: 23[10], FP IV 759; KSA XIII 60: 23[1], FP IV 751.

92. KSA XII 87-88: 2[57], FP IV 92.

93. KSA XI 50: 25[137], FP III 481. 